\title{
Two Case Studies of Tornadoes Associated with Cold-Core 500-mb Lows, and Operational Warning Recommendations
}

\author{
AMY E. BETTWY \\ NOAA/National Weather Service, Sioux Falls, South Dakota
}

(Manuscript received 17 April 2014; review completed 27 October 2014)

\begin{abstract}
Two cases of tornadoes associated with cold-core 500-mb lows are presented in order to continue building a formal documented catalog of these events. Although environments associated with these tornadoes are considered atypical for strong tornadoes with supercells, one of these cases produced a tornado that resulted in F2 damage while the other case missed useful damage indicators. These events do not follow the classical conceptual model of environments capable of producing strong tornadoes because there is less surface moisture and deep-layer buoyancy. As such, these events are often poorly anticipated or missed completely by forecasters. It is important to build a catalog and continue to adapt the conceptual model of these events in order to prepare and warn for them better and more efficiently in the future. Recommendations are provided on how to handle these events in both the outlook period $(>1 \mathrm{~h})$ and for warnings in an effort to improve both situational awareness and statistics.
\end{abstract}

\section{Introduction}

While tornadoes associated with cold-core 500-mb lows have been acknowledged and studied in the past, a climatology of these tornadoes was not developed until Davies and Guyer (2004, hereafter DG04). DG04 showed that tornadic cells associated with cold-core lows, when dewpoint temperatures of $5^{\circ} \mathrm{C}$ to $9^{\circ} \mathrm{C}$ (low to mid $40 \mathrm{~s}^{\circ} \mathrm{F}$ ) or greater were present within $320 \mathrm{~km}$ $(200 \mathrm{mi})$ of the $500-\mathrm{mb}$ low center, were not uncommon across the Plains states, with $28.9 \%$ of cold-core lows producing tornadoes in the 5-yr period (1999-2003) across the northern Plains, and 23.6\% across the southern Plains. It is important to note that these cases were not categorized as "cold-air funnels," where the tornado was located to the west of the surface low and a cold frontal passage occurred 18-24 $\mathrm{h}$ in advance (Cooley 1978). The tornadoes in these cases were located east of the surface low and were associated with the warm sector.

DG04 developed a schematic [updated in Davies (2006a), Fig. 1] noting important features of the tornadic environments in order to increase forecaster awareness and pattern recognition. Given a cold-core low is present (see DG04 for definition used), they

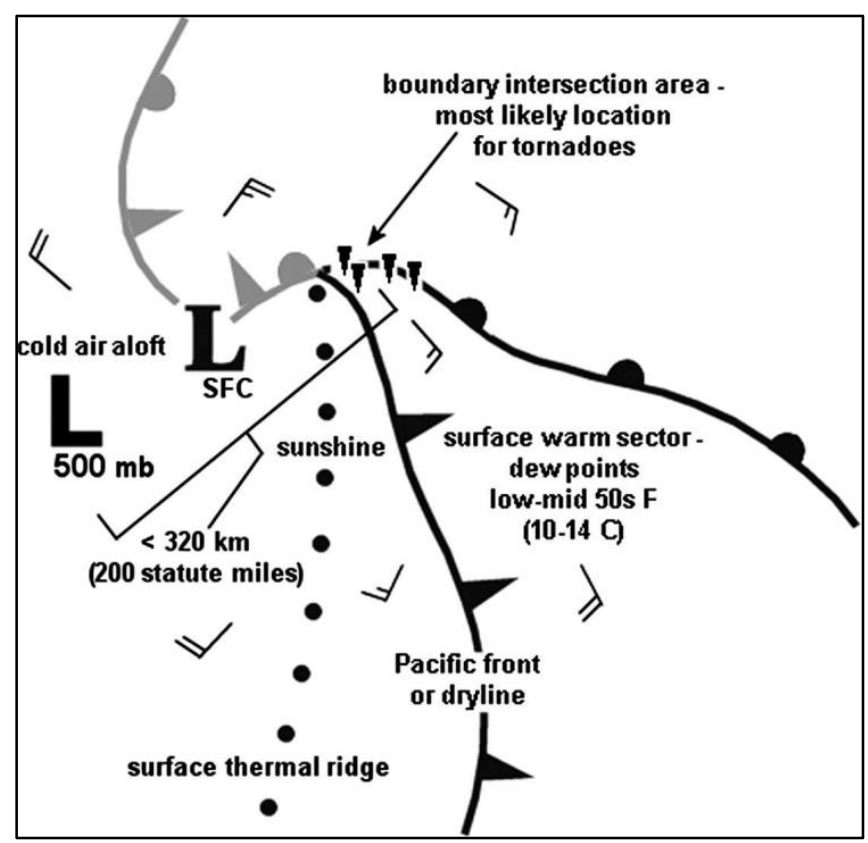

Figure 1. Composite schematic from Davies (2006a) summarizing the most common and most important features found with tornadic 500-mb cold-core low events. Click image for an external version; this applies to all figures hereafter. 
showed that the most important discriminating factors between nontornadic and tornadic cases were "surface features and characteristics in proximity to the midlevel lows." These features shown in the Davies (2006a) schematic include the presence of a welldefined warm sector with dewpoints from $10^{\circ} \mathrm{C}$ to $13^{\circ} \mathrm{C}$ (low to mid $50 \mathrm{~s}^{\circ} \mathrm{F}$ ), and a boundary intersection and surface low located within $320 \mathrm{~km}$ (approximately $200 \mathrm{mi}$ ) of the 500-mb low center (Fig. 1). The presence of a boundary intersection usually results in an area of maximized surface vertical vorticity. Furthermore, Davies (2006a) highlights the existence of an axis of surface heating that ends near the boundary intersection (Fig. 1). The surface heating increases low-level lapse rates, which can result in an increased potential for rapid parcel ascension and stretching in the low levels (Davies 2006b). Finally, according to DG04 and Davies (2006a), the tornadic storms most often occur near the boundary intersection along the warm front where vertical vorticity and convergence are enhanced. Using this schematic and specific occurrences, Davies (2006a) documented four cases of tornadoes associated with cold-core lows, and showed how each fit into the aforementioned conceptual schematic. This paper adds two additional events to the documented cases (Fig. 2a) and exhibits how each fits into Davies's noted features. The first case is from 23 September 2004 when two tornadoes that produced F1 and F2 damage developed quickly along the South Dakota and Minnesota border and destroyed a newly constructed house, among other structures and crops (Fig. 2b and Fig. 3). The second case is from 26 May 2007 when a waterspout that developed over Lake Winnibigoshish in northern Minnesota was spotted by fishermen in boats. In both cases, the tornadoes occurred without convective warnings from the National Weather Service (NWS) because of a lack of tornadic radar signatures, and because instability and moisture was thought to be too low. Because the overall instability was relatively small, composite parameters such as the significant tornado parameter (STP; Thompson et al. 2003) were not in the favorable range for tornadic supercells. Nevertheless, both cases were within the $2 \%$ probabilistic tornado graphic issued by the Storm Prediction Center (SPC) in the Day 1 Outlooks prior to the tornado occurrences. One of the purposes of this paper is to increase forecaster awareness and pattern recognition of these situations for better anticipation and warning operations of these potentially significant tornadic events by adding to the cases documented by
Davies (2006a). Another purpose of this paper is to provide outlook and warning recommendations for local NWS Weather Forecast Offices (WFOs).

\section{Case studies}

The two cases presented in this paper are part of the author's personal experience from working at the respective NWS WFOs at the times of tornado occurrences. Values of environmental parameters were determined from diagnostic plan-view mesoanalyses from the SPC (Bothwell et al. 2002) and Rapid Update Cycle (RUC) point analysis soundings (Thompson et al. 2003). Observational data included visible satellite imagery, Weather Surveillance Radar-1988 Doppler (WSR-88D) data, upper-air radiosonde analyses data, and surface observations. The RUC analysis sounding used for the 23 September 2004 case is nearest the time of tornado events (within $5 \mathrm{~min}$ following the tornadoes) in a location-Wheaton, Minnesota (KETH) - to represent the warm sector and inflow air mass that was ingested into the storms. The location of the RUC analysis soundings used for the 26 May 2007 case was Longville, Minnesota (KXVG), and the times were chosen to represent the pre-warm front (about $1.25 \mathrm{~h}$ before the tornado) environment, the warm sector (about $15 \mathrm{~min}$ prior to tornado occurrence), and post-dryline (about $45 \mathrm{~min}$ after the tornado) environment in proximity to the tornado. Level-II volumetric WSR-88D data from Aberdeen, South Dakota (KABR), and Duluth, Minnesota (KDLH), were archived by the National Climatic Data Center (www.ncdc.noaa.gov/nexradinv/), and radar images used in this paper were captured using GR Level II Analyst (www.grlevelx.com/gr2analyst/) or the Advanced Weather Interactive Processing System (AWIPS). Because instability is typically more limited and concentrated in the low levels in cold-core 500-mb cases (Davies 2006a), and Guyer and Davies (2006) used surface dewpoints as a key ingredient of their study; surface-based (SB) lifted parcels were used to assess thermodynamic parameters in these cases.

\section{a. 23 September 2004}

On the afternoon of 23 September 2004 just before 2000 UTC, two tornadoes, later rated F1 and F2, quickly developed and moved along the Minnesota and South Dakota border. Although the 0-6-km bulk wind difference (BWD) across the area was approximately $20 \mathrm{~m} \mathrm{~s}^{-1}$ (40 kt, not shown), suggesting any convection that developed could become 


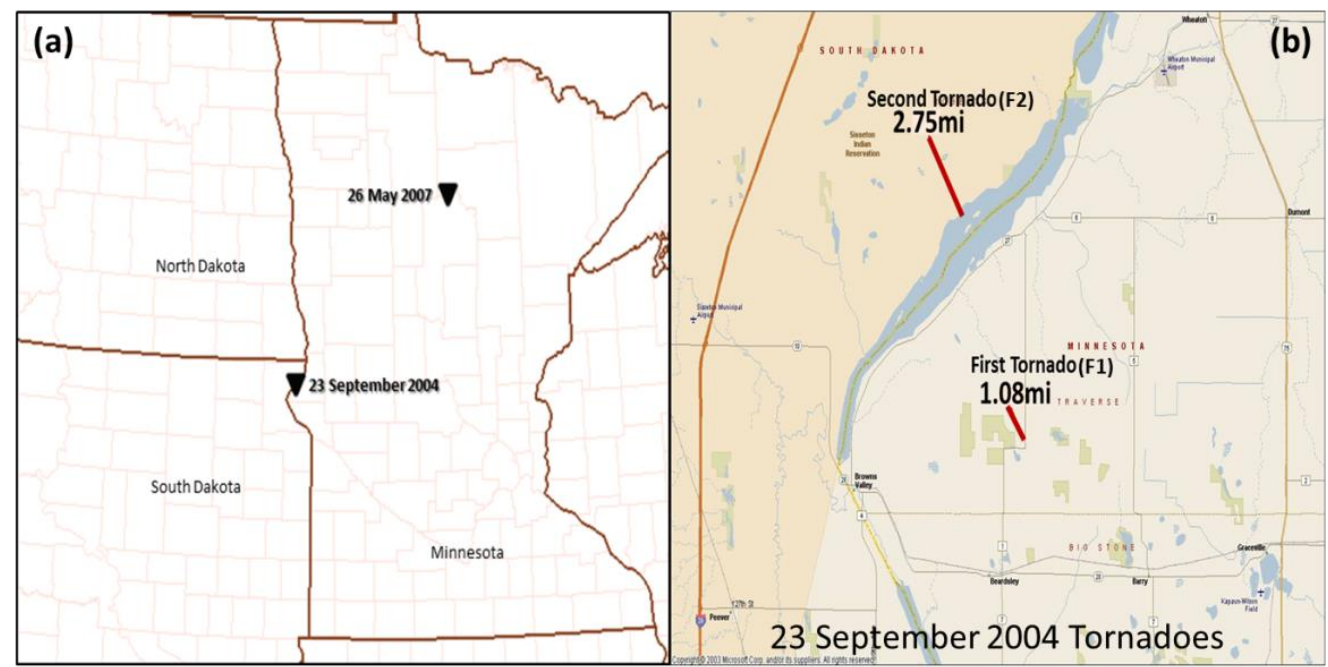

Figure 2. (a) Locations and dates of the tornadoes discussed in the two cases presented in this paper. (b) Locations, ratings, and paths of the two tornadoes that occurred with the 24 September 2004 case, courtesy of the storm damage survey completed by NWS, Aberdeen, SD.

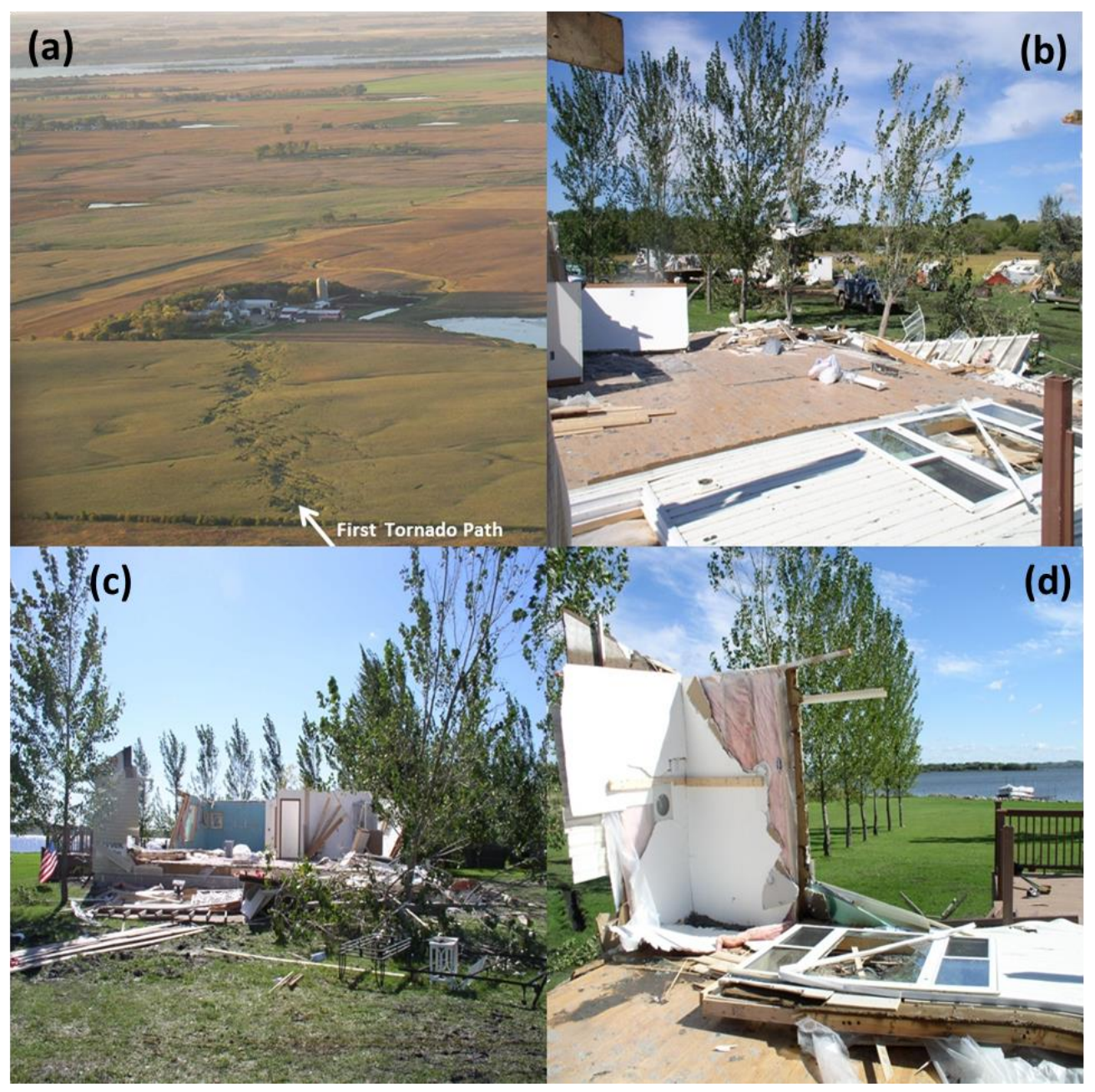

Figure 3. (a) Aerial evidence of the first tornado approaching a farmhouse in west-central MN on 23 September 2004. (b, c, and d) F2 damage from the second tornado on 23 September 2004 to a newly constructed home in northeastern SD. Photos courtesy of NWS, Aberdeen, SD. 
supercellular (Rasmussen and Blanchard 1998), it was unclear initially to NWS forecasters what had caused the damage because WSR-88D radar signatures from KABR leading up to and at the time of the tornadoes (approximately 1958 UTC) were not indicative of a tornadic supercell (Fig. 4). Also, deep-layer buoyancy did not appear favorable for "typical" or classic supercells as SB convective available potential energy (CAPE) was $<600 \mathrm{~J} \mathrm{~kg}^{-1}$. For comparison, in the study by Thompson et al. (2003), the sounding-derived median value of mean-layer CAPE (MLCAPE) for significant tornadic supercells was $2152 \mathrm{~J} \mathrm{~kg}^{-1}$, and $1835 \mathrm{~J} \mathrm{~kg}^{-1}$ for supercells that produced weak tornadoes, suggesting that the environment was not very favorable for tornadic supercells in this case. Still, two hours prior to the tornado occurrences, SPC issued a mesoscale discussion highlighting the potential for tornadoes in a favorably sheared environment with very marginal instability. The NWS aerial and ground storm surveys indicated the damage was indeed caused by two tornadoes rated F1 and F2 in strength (Fig. 3).

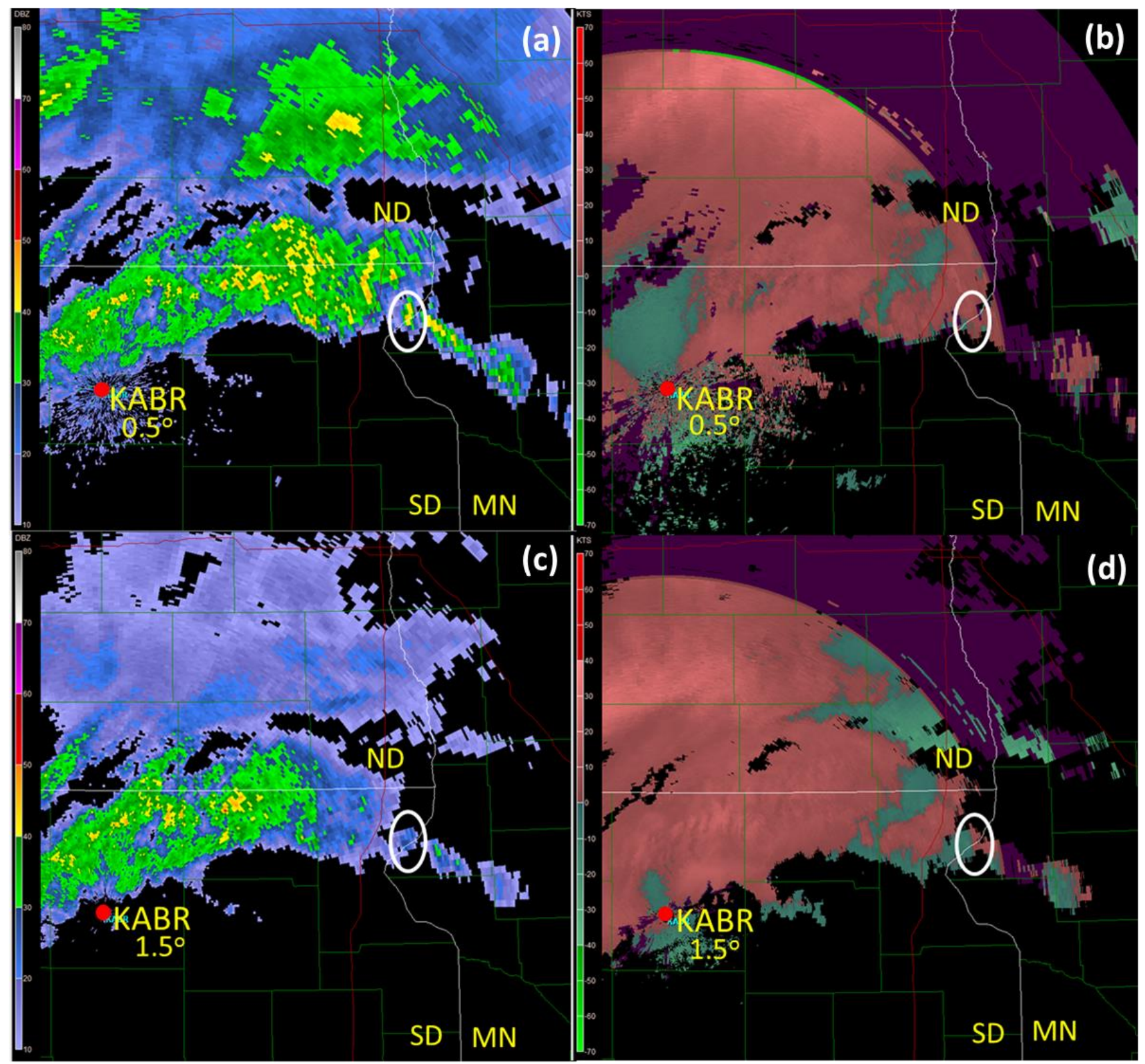

Figure 4. (a and b) $0.5^{\circ}$ base reflectivity and storm-relative velocity radar images from the KABR WSR-88D at 1958 UTC. (c and d) $1.5^{\circ}$ reflectivity and storm-relative velocity radar images from the KABR WSR-88D at 1958 UTC. The scans are nearest to the time of the tornadoes on 23 September 2004. The white oval encompasses the tornadic cell in all images. 
At 2000 UTC, the surface low pressure center was located approximately $30 \mathrm{~km}(20 \mathrm{mi})$ southeast of Aberdeen, South Dakota (Fig. 5), while a midlevel, cold-core closed low was centered about $32 \mathrm{~km}$ (20 mi) northwest of Huron, South Dakota. Approximately $200 \mathrm{~km}(130 \mathrm{mi})$ to the northeast of the northeastwardmoving 500-mb low center, visible satellite and surface observations indicated the presence of a boundary intersection of the warm front and dryline near the South Dakota and Minnesota border. Dewpoints were around $15^{\circ} \mathrm{C}$ (upper $50 \mathrm{~s}^{\circ} \mathrm{F}$ ) south of the warm front while around $10^{\circ} \mathrm{C}\left(50^{\circ} \mathrm{F}\right)$ behind the dryline. Axes of partial sunshine enhanced surface heating between the warm front and dryline, as well as south and west of the dryline. These axes resulted in thermal surface ridging that extended to the boundary intersection.

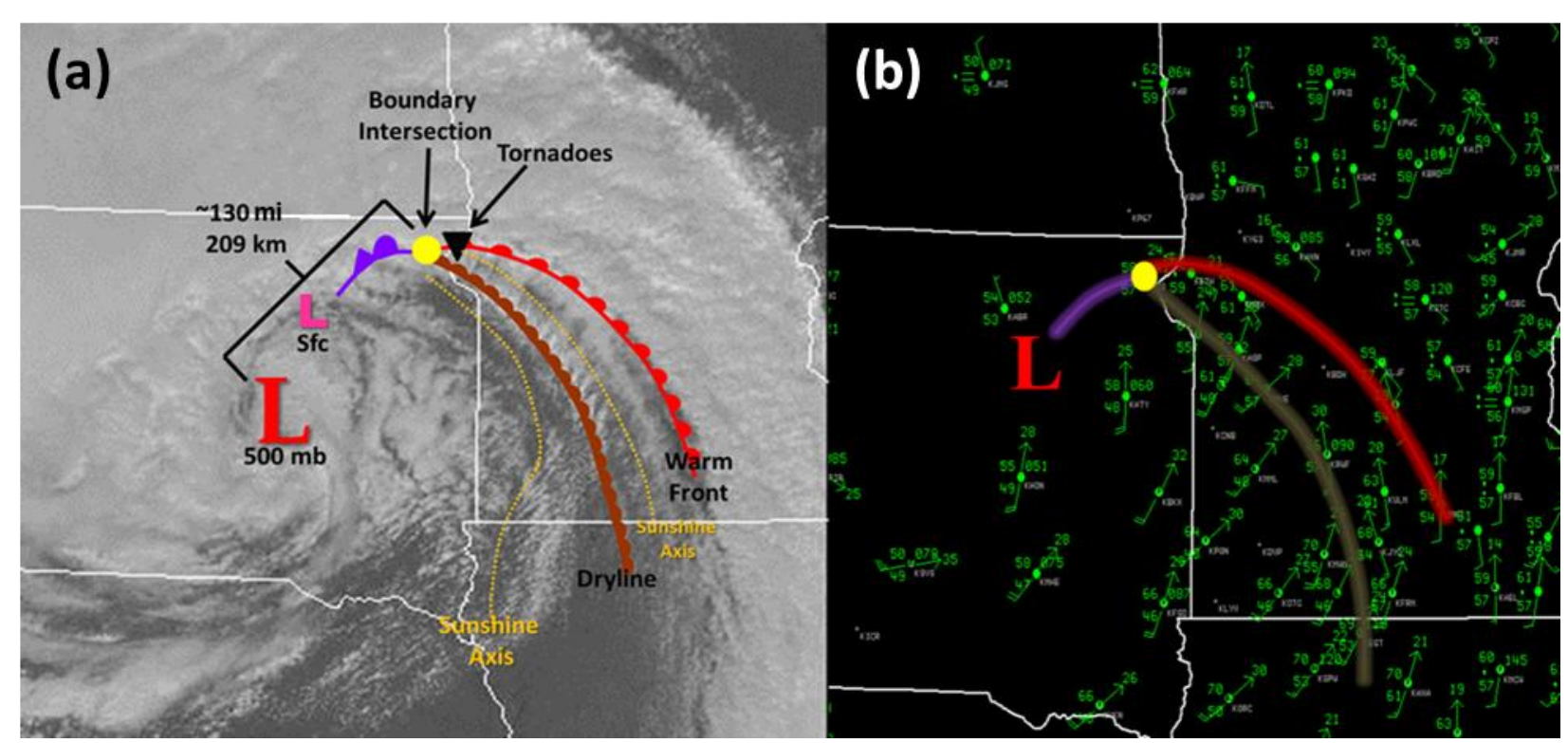

Figure 5. (a) Summary schematic of surface features and the upper-low location for the 23 September 2004 cold-core low tornadic event superimposed on associated visible satellite image at 1955 UTC. (b) 2000 UTC surface plot $\left({ }^{\circ} \mathrm{F}\right)$ and feature analysis on 23 September 2004. The red, brown, and purple lines are the analyzed warm front, dryline, and occluded front, respectively.

A closer view of the $0.5^{\circ}$ base reflectivity KABR WSR-88D radar image from Fig. 4a at 1958 UTC (Fig. $6 a)$ showed the maximum reflectivity was only 46 $\mathrm{dBZ}$ with the tornadic cell. The line of convection along the dryline was moving north-northwest (from $\left.175^{\circ}\right)$ at $18 \mathrm{~m} \mathrm{~s}^{-1}(35 \mathrm{kt})$, and there was no cloud-toground lightning within the cell detected via the National Lightning Data Network (owned and operated by Vaisala). A closer view of the corresponding storm-relative velocity (SRV) product (Fig. 6b) also showed no clear signs of storm-scale rotation, with weak outbound velocities of 3 to $5 \mathrm{~m} \mathrm{~s}^{-1}$ ( 5 to $10 \mathrm{kt}$ ) and weak inbound velocities of 3 to $5 \mathrm{~m} \mathrm{~s}^{-1}$ (5 to $10 \mathrm{kt}$ ) associated with a radial divergence signature located around $2.2 \mathrm{~km}(7250 \mathrm{ft})$ in the $0.5^{\circ}$ scan. Looking back at Fig. $4 \mathrm{~d}$ on the $1.5^{\circ}$ scan, a divergent pattern also showed a radial velocity difference of only $12.5 \mathrm{~m} \mathrm{~s}^{-1}(24.3 \mathrm{kt})$ that was located around $4.6 \mathrm{~km}$ (15 $100 \mathrm{ft})$.
So, as seen in Figs. 4 and 6, KABR WSR-88D radar data showed no rotational velocity, nor any typical characteristics of a supercell with a strong updraft such as a mesocyclone, weak-echo region (WER), or a bounded weak-echo region (BWER). Moreover, RUC analysis SBCAPE values in the area appeared quite meager, with only $184 \mathrm{~J} \mathrm{~kg}^{-1}$ at Wheaton, Minnesota (KETH), per the unaltered 2000 UTC RUC analysis sounding (not shown). As noted before, these factors all suggested an absence of significant tornado potential to NWS forecasters.

However, if the 2000 UTC KETH RUC analysis sounding (Fig. 7) was modified using a SB lifted parcel based on the actual 2000 UTC KETH surface observation, and the virtual temperature correction applied (Doswell and Rasmussen 1994), computed SBCAPE increased from $184 \mathrm{~J} \mathrm{~kg}^{-1}$ to $565 \mathrm{~J} \mathrm{~kg}^{-1}$, more than twice the unaltered, unmodified model analysis value. This large difference in CAPE between 

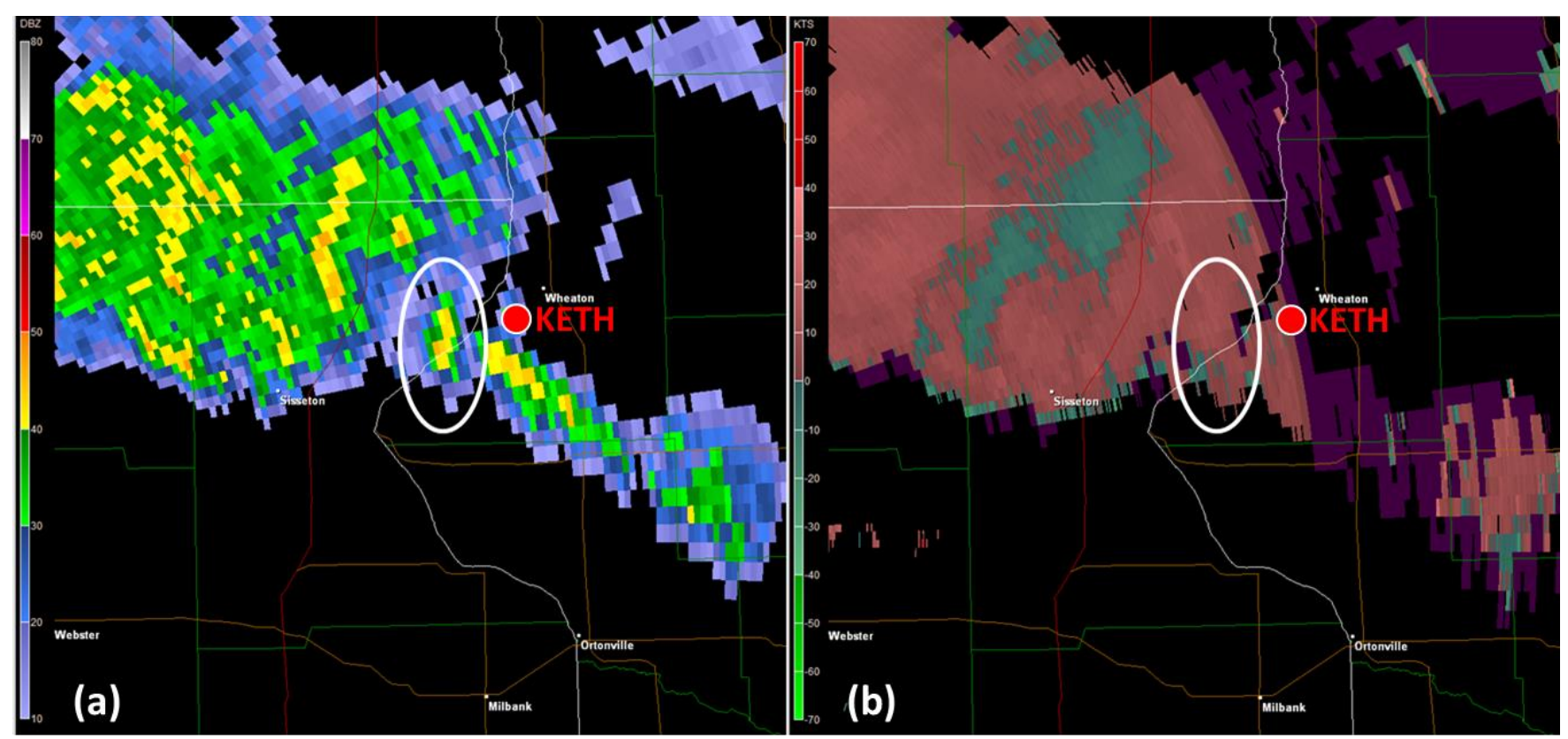

Figure 6. Same as Fig. 4 except for a closer view of the $0.5^{\circ}$ (a) base reflectivity and (b) storm-relative velocity at 1958 UTC. The white oval encompasses the tornadic cell, and the red dot denotes the location of the KETH AWOS site.

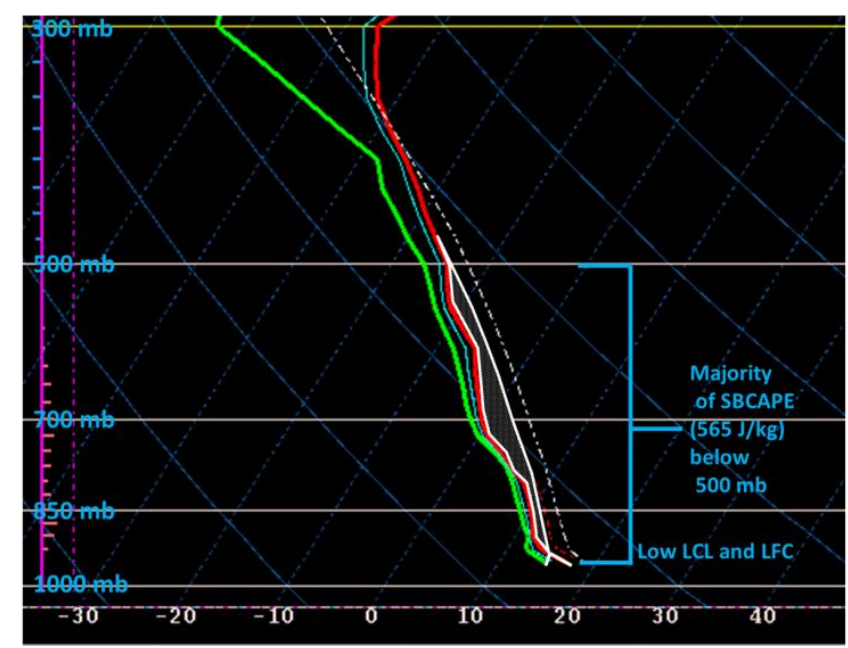

Figure 7. Skew $T-\log p$ diagram of the RUC analysis profile for Wheaton, MN, at 2000 UTC 23 September 2004 modified to reflect the 1955 UTC KETH surface observation $\left(\mathrm{T}=17^{\circ} \mathrm{C}\right.$, $\mathrm{T}_{\mathrm{d}}=15^{\circ} \mathrm{C}$ ) and to account for the virtual temperature correction. The red and green lines represent temperature and dewpoint profiles, respectively. The white outlined area with a dotted fill represents the SBCAPE area.

modified and unmodified model analysis soundings emphasizes the importance of local updating of model data via current observed surface observations for NWS forecasters to accurately analyze and recognize the tornadic threat in some cold-core situations. Additionally, even though the SBCAPE was less than the 25th percentile for tornadic 500-mb closed-cold core low environments in the 2006 Guyer and Davies study (Table 1), notice that most of the CAPE was located below 500mb (Fig. 7), typical of many coldcore tornado environments (Davies 2006a). This shallow but ample buoyancy likely aided vertical stretching in updrafts and was a possible important ingredient for "discriminating between environments supportive of significant tornadoes and those that are not" (Rasmussen 2003).

Table 1. Tabular comparison of the median and 25th/75th percentiles for environmental parameters for the database of closed cold-core 500-mb lows (C500L) associated with tornadoes per Guyer and Davies (2006) and the environmental parameters for the 23 September 2004 and 26 May 2007 cases presented in this paper.

\begin{tabular}{|c|c|c|c|}
\hline $\begin{array}{l}\text { Environmental } \\
\text { Parameter }\end{array}$ & $\begin{array}{l}\text { C500L with } \\
\text { tornadoes } \\
\text { database }\end{array}$ & 23 Sep 2004 & 26 Мay 2007 \\
\hline 0-1-km EHI & $\begin{array}{ll}\text { 25th: } & 0.2 \\
\text { Median: } & 0.7 \\
\text { 75th: } & 1.1\end{array}$ & -0.15 & 0.20 \\
\hline 0-1-km VGP & $\begin{array}{ll}\text { 25th: } & 0.24 \\
\text { Median: } & 0.43 \\
\text { 75th: } & 0.57\end{array}$ & 0.31 & 0.39 \\
\hline $\operatorname{SBCAPE}\left(\mathrm{J} \mathrm{kg}^{-1}\right)$ & $\begin{array}{lr}\text { 25th: } & 765 \\
\text { Median: } & 1221 \\
\text { 75th: } & 1756\end{array}$ & 565 & 692 \\
\hline
\end{tabular}

Another important factor was the location of a surface heating axis, evident with the sunshine axis marked in Fig. 5a and extending from southeast to northwest under the cold air aloft just behind the dryline to near the surface boundary intersection area (Davies 2006a). This resulted in near-dry adiabatic 
lapse rates in the lowest 2 or $3 \mathrm{~km}$ above the surface (not shown) that, when intruding into the moisture axis, likely helped to increase CAPE, remove any capping, and further enhance low-level stretching (Davies 2006b). In fact, the SPC mesoanalysis depiction of low-level lapse rates (not shown) indicated a $1.5^{\circ} \mathrm{C} \mathrm{km}^{-1}$ increase in $0-3-\mathrm{km}$ lapse rate from 1600 UTC to 2200 UTC on 23 September 2004 near the location of the tornadoes.

Finally, axes of maximized vertical vorticity along the surface boundaries and near the boundary intersection were evident in the SPC mesoanalysis depiction (see Fig. 8a), along with some degree of low-level shear [see Fig. 8b; 0-1-km BWD of $7 \mathrm{~m} \mathrm{~s}^{-1}$ (13 kt)]. This $0-1-\mathrm{km}$ BWD implies the presence of low-level horizontal vorticity (Togstad et al. 2011).
The tilting and stretching of available environmental vorticity (Davies-Jones et al. 1990), along with stretching of increased pre-existing vertical vorticity near the boundary intersection, likely helped support tornado development in this case. Of particular importance, the aforementioned presence of low-level CAPE and also steep low-level lapse rates from behind the dryline likely enhanced the low-level tilting and stretching potential beyond what would be immediately evident when looking only at the relatively small total CAPE magnitudes. Indeed, the two tornadoes developed with a cell embedded in the line of convection just east of the surface boundary intersection and at the nose of sunshine and surface heating from just behind the dryline.

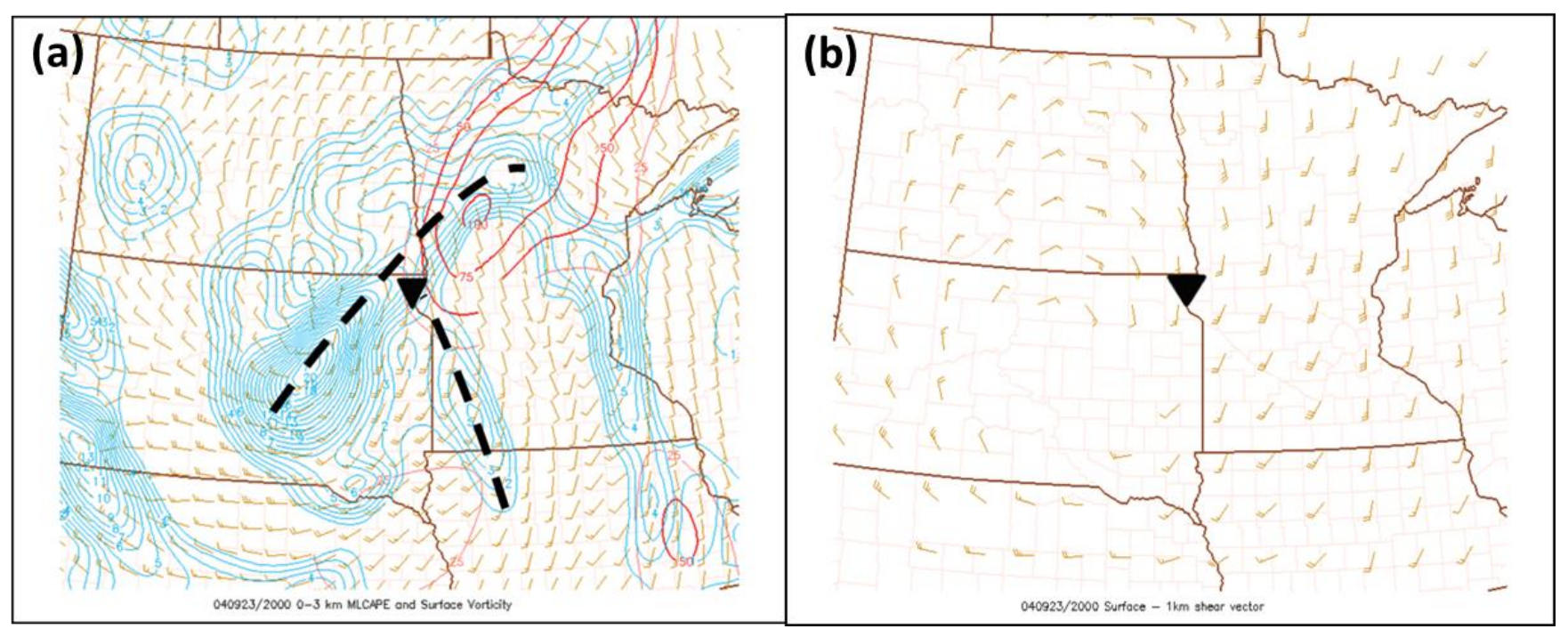

Figure 8. (a) Surface vorticity (blue; $1.0 \times 10^{-5} \mathrm{~s}^{-1}$ contour interval) and 0-3-km MLCAPE (red; $25 \mathrm{~J} \mathrm{~kg}^{-1}$ contour interval) from SPC mesoanalysis at 2000 UTC 23 September 2004. The black dashed lines highlight the axis of maximum surface vorticity. (b) 0-1-km shear vector from SPC mesoanalysis at 2000 UTC 23 September 2004. The black triangle denotes the location of the tornadoes.

\section{b. 26 May 2007}

On a Saturday afternoon (1915 UTC) during the first month of the ever-popular fishing season in northcentral Minnesota, several fishermen on Lake Winnibigoshish were witness to a waterspout associated with a 500-mb cold-core low (Fig. 9). Forecasters at the NWS in Duluth, Minnesota, did not anticipate this tornado because, as in the prior case, there was a lack of tornadic or supercell signatures on KDLH WSR-88D radar imagery (Fig. 10). Also, despite favorable deep-layer shear [0-6-km BWD of approximately $\left.18 \mathrm{~m} \mathrm{~s}^{-1}(35 \mathrm{kt})\right]$ that suggested convection could become supercellular, moisture and buoyancy looked insufficient with surface dewpoints from $8^{\circ} \mathrm{C}$ to $12^{\circ} \mathrm{C}$ (upper $40 \mathrm{~s}^{\circ} \mathrm{F}$ and lower $50 \mathrm{~s}^{\circ} \mathrm{F}$ ), and SBCAPE $<250 \mathrm{~J} \mathrm{~kg}^{-1}$ per the SPC mesoanalysis (not shown). However, SPC did highlight a tornado potential in the Day 1 Outlook, stating, "enhanced shear [in the] vicinity [of the] warm front could result in isolated supercells/tornadoes provided air mass can destabilize sufficiently." Pictures after the fact proved that a tornado did occur and showed again that the tornado potential associated with cold-core $500-\mathrm{mb}$ lows should be assessed.

At 1900 UTC, the surface low was located about $32 \mathrm{~km}(20 \mathrm{mi})$ northeast of Thief River Falls, Minnesota (Fig. 11), while the upper low, with a 500$\mathrm{mb}$ minimum temperature of $-20^{\circ} \mathrm{C}$, was situated to 


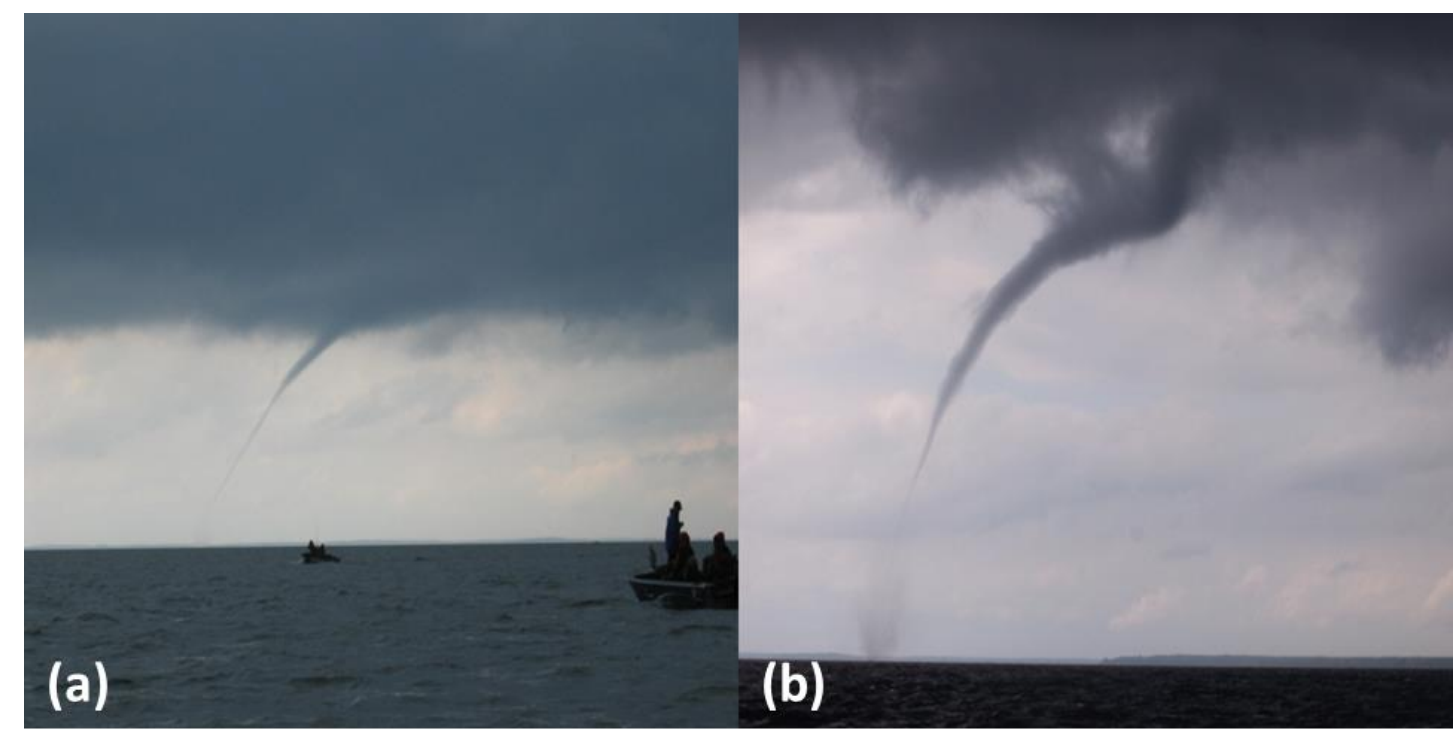

Figure 9. Photographs of waterspout associated with the 500-mb cold-core low on Lake Winnibigoshish on 26 May 2007. Photos used with permission, courtesy of (a) Mark Podominick and (b) Lisa Stangler.

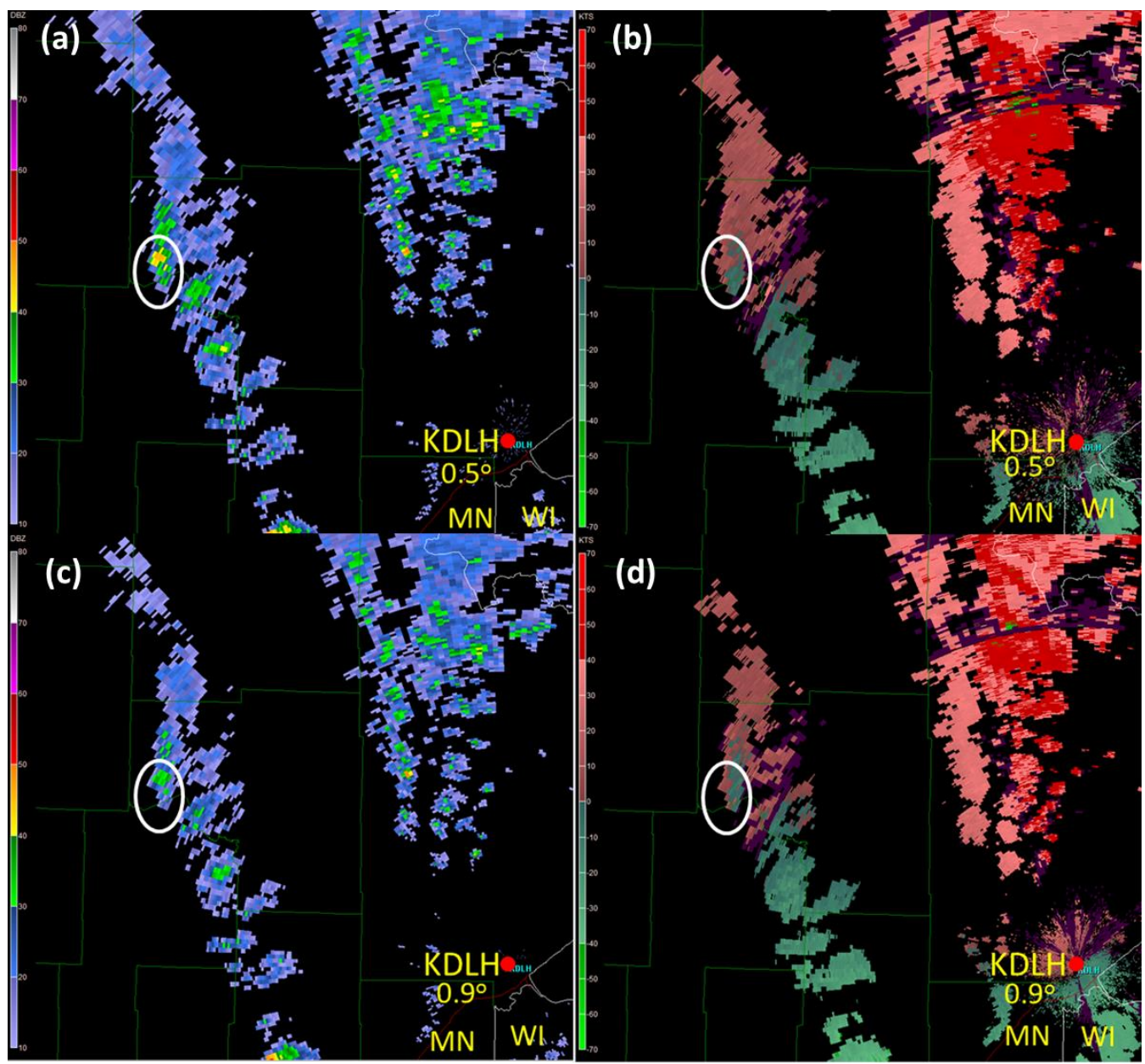

Figure 10. ( $a$ and b) $0.5^{\circ}$ base reflectivity and storm-relative velocity radar images from the KDLH WSR$88 \mathrm{D}$ at 1914 UTC. (c and d) $0.9^{\circ}$ reflectivity and storm-relative velocity radar images from the KDLH WSR-88D at 1914 UTC. The scans are nearest to the time of the tornado on 26 May 2007. The white oval encompasses the tornadic cell in all images. 


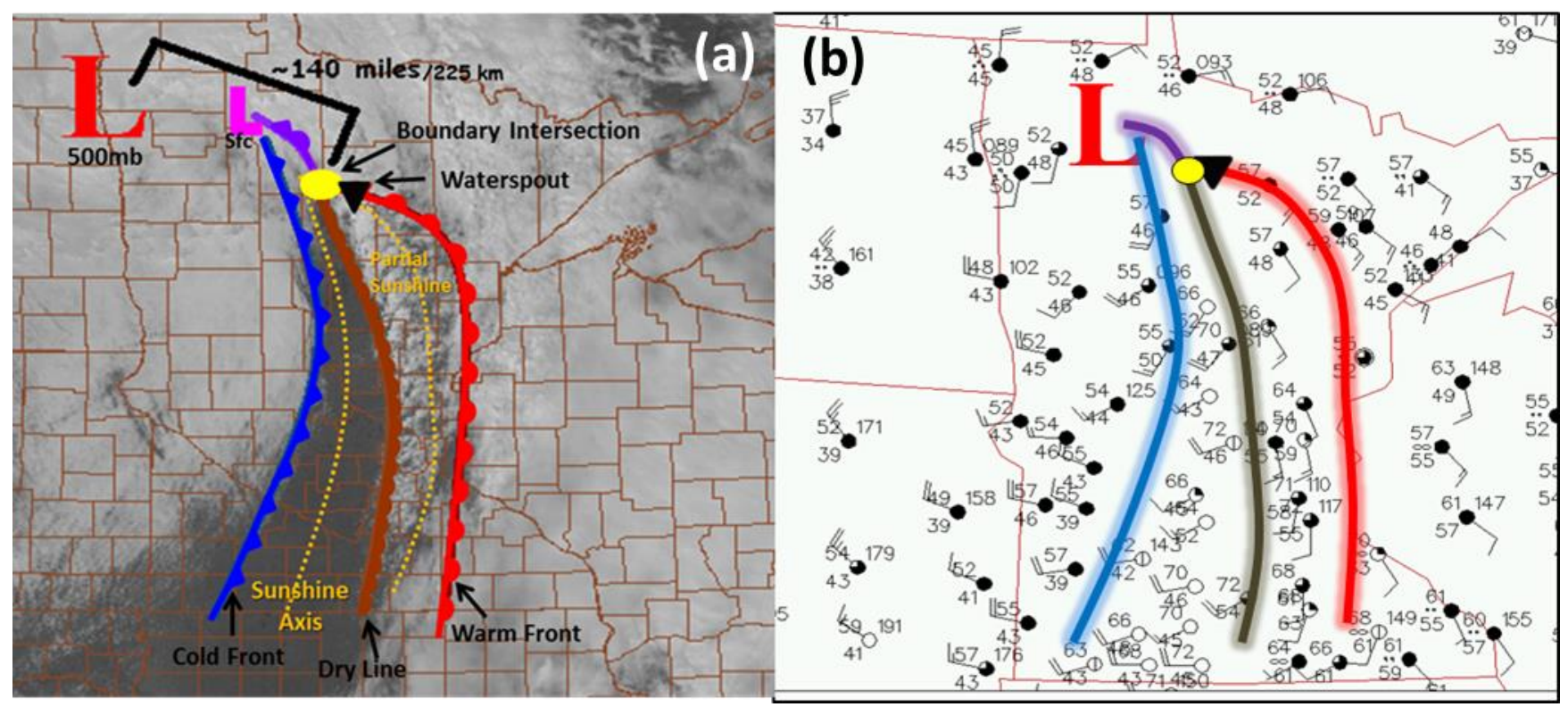

Figure 11. (a) Summary schematic of surface features and upper-low location for the 26 May 2007 cold-core low tornadic event superimposed on associated visible satellite image at 1915 UTC. (b) 1900 UTC surface plot $\left({ }^{\circ}\right.$ F) (courtesy of Plymouth State Weather Center) and feature analysis on 26 May 2007. The red, brown, and purple lines are the analyzed warm front, dryline, and occluded front, respectively.

the west along the North Dakota and Minnesota border (Fig. 12). A warm front had developed owing to differential daytime heating in an axis of partial sunshine. This warm front intersected the dryline just to the west of Lake Winnibigoshish and then extended northwest as an occluded front to the surface low (Fig. 11). Another axis of full sunshine followed the dryline and was located ahead of the surface cold front. There was enhanced vertical vorticity present at and near the boundary intersection (Fig. 13), which was located roughly $225 \mathrm{~km} \mathrm{(140} \mathrm{mi)} \mathrm{east-southeast} \mathrm{of} \mathrm{the}$ eastward-moving 500-mb low center. Low-level wind shear was also present [0-1-km BWD of $8 \mathrm{~m} \mathrm{~s}^{-1}$ (15 $\mathrm{kt}$ ), not shown] that suggested some horizontal vorticity was available for tilting and stretching into the updraft. Low-level stretching also likely was enhanced by the intrusion of surface heating, which allowed for an increase in low-level instability with an approximate increase of $1.0^{\circ} \mathrm{C} \mathrm{km}^{-1}$ in the lowest $3 \mathrm{~km}$ from 1800 UTC to 2000 UTC (Fig. 14). A closer view of the KDLH WSR-88D radar imagery from Fig. 10a at 1914 UTC (Fig. 15a) showed a line of convective showers along the dryline. Echo tops were only around $6 \mathrm{~km}(20000 \mathrm{ft})$, no cloud-to- ground lightning was detected in the cell, and it had a maximum reflectivity of $47 \mathrm{dBZ}$ (Fig. 15a). The KDLH radar was approximately $160 \mathrm{~km}(100 \mathrm{mi})$ from the storm so that the center beam height from the $0.5^{\circ}$ elevation angle

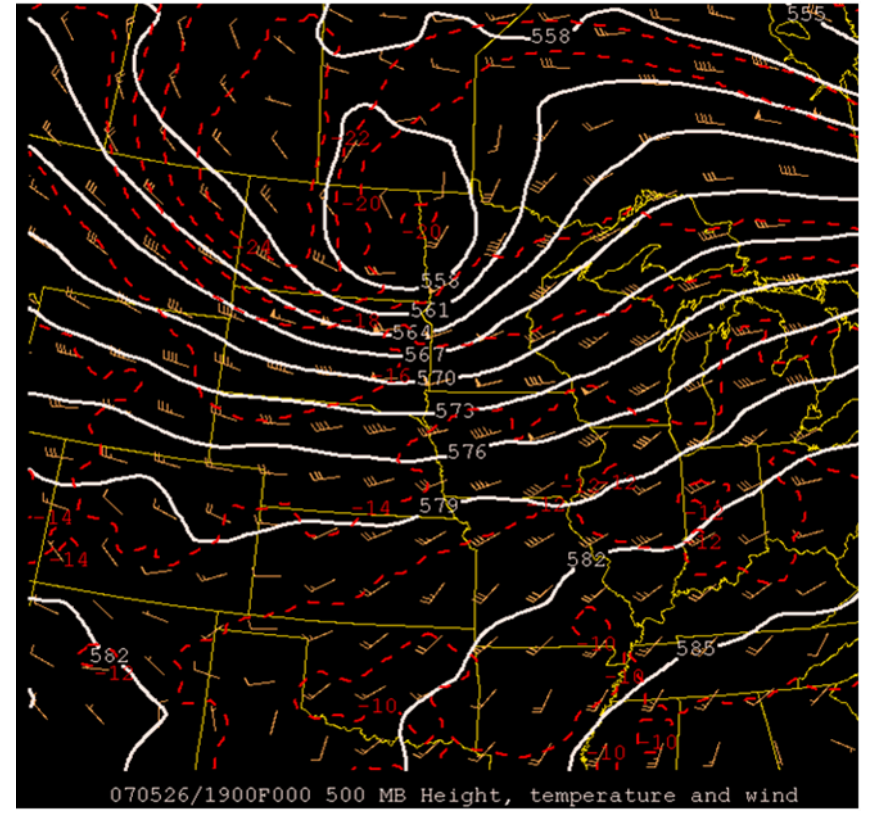

Figure 12. The 1900 UTC 26 May 2007 RUC 500-mb height analysis (30-m contour interval) in white, $500-\mathrm{mb}$ temperatures $\left(2^{\circ} \mathrm{C}\right.$ contour interval) in dashed red, and $500-\mathrm{mb}$ winds (barbs in $\mathrm{kt}$; multiply by 0.5144 for $\mathrm{m} \mathrm{s}^{-1}$ ) in orange.

was approximately $3500 \mathrm{~m} \mathrm{(10} \mathrm{600} \mathrm{ft).} \mathrm{A} \mathrm{closer} \mathrm{view}$ of the SRV signatures (Fig. 15b) at this height only showed a weak divergent signature with an $8 \mathrm{~m} \mathrm{~s}^{-1}$ (15 kt) maximum inbound and an $8 \mathrm{~m} \mathrm{~s}^{-1}(15 \mathrm{kt})$ maximum outbound. 


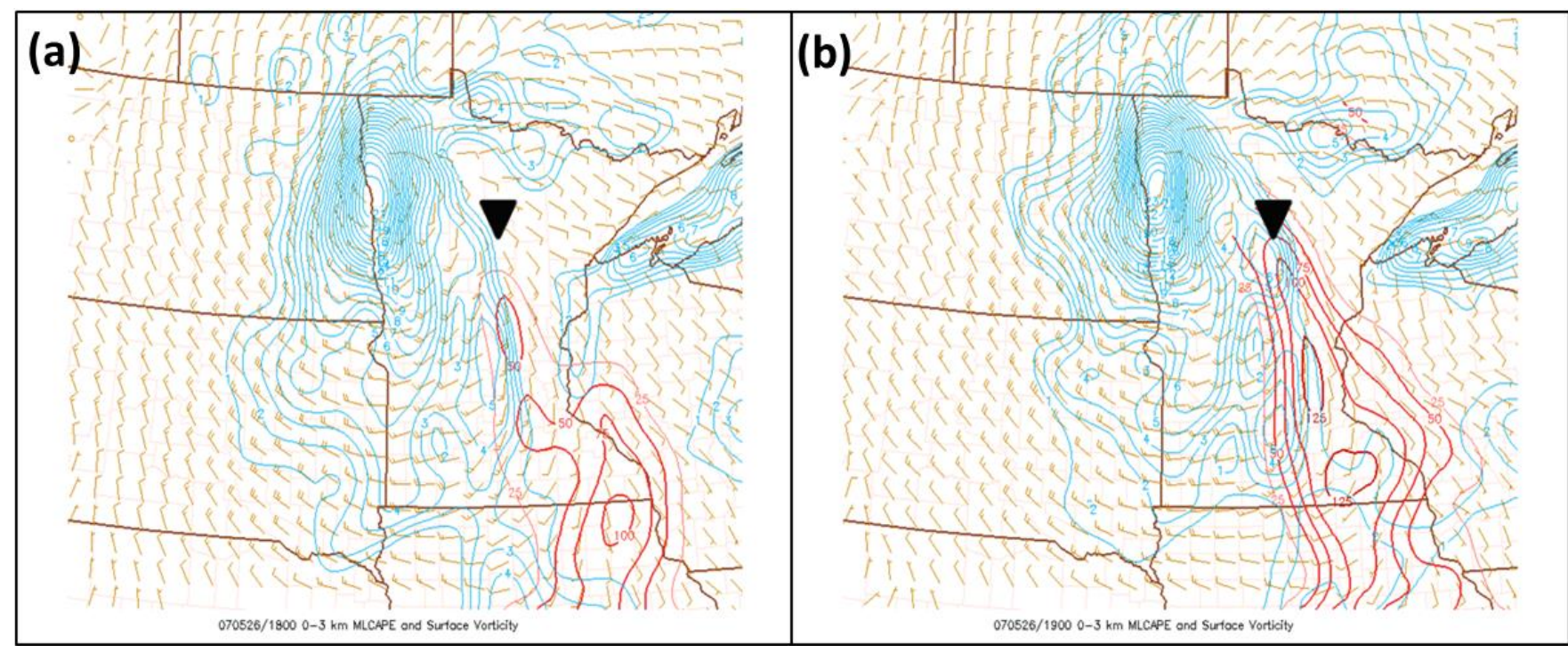

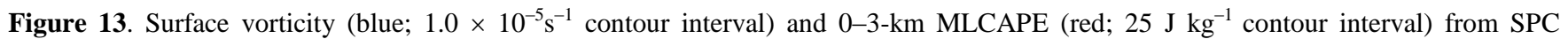
mesoanalysis at (a) 1800 UTC and (b) 1900 UTC 26 May 2007. The black triangle denotes the location of the waterspout.
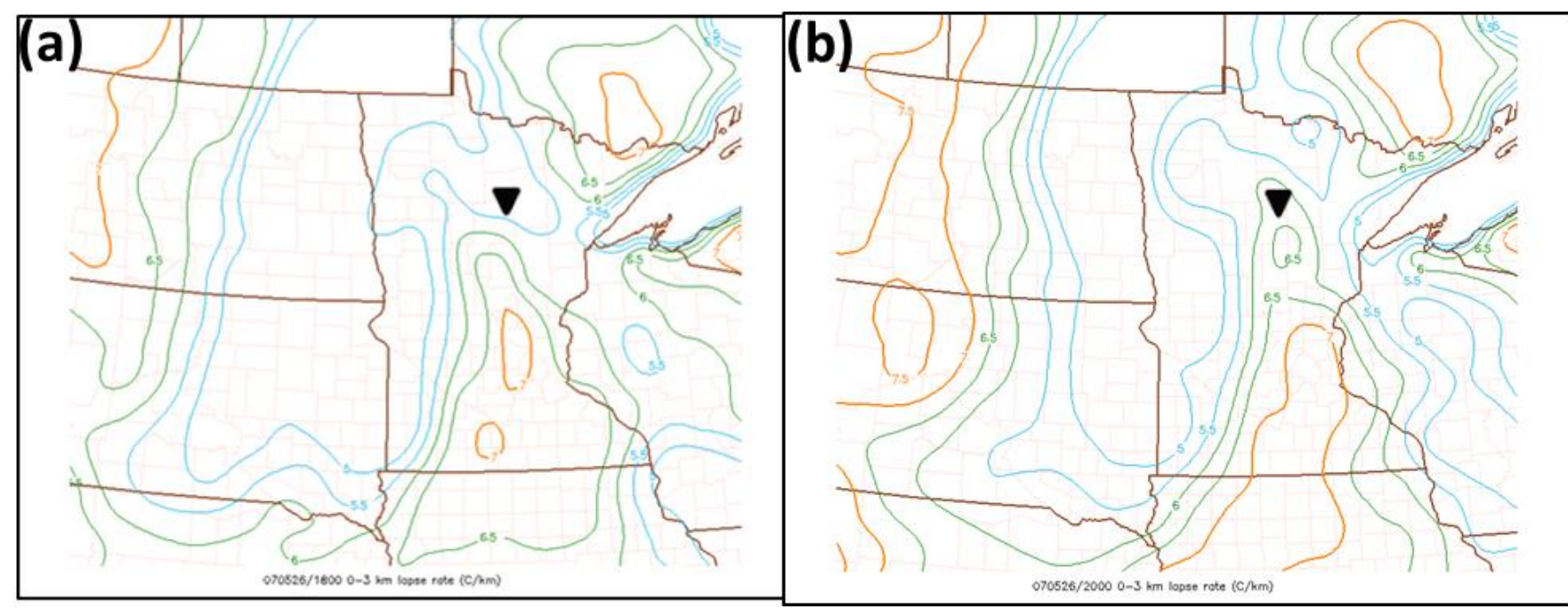

Figure 14. 0-3-km lapse rates $\left(0.5^{\circ} \mathrm{C} \mathrm{km}^{-1}\right.$ interval) from SPC mesoanalysis at (a) 1800 UTC and (b) 2000 UTC 26 May 2007 . The black triangle denotes the location of the waterspout.

Hourly RUC analysis soundings from Longview, Minnesota (KXVG), showed the evolution of the thermodynamic parameters quite well in the low levels as the warm front and dryline passed. Figures $16 \mathrm{a}-\mathrm{c}$ show the 1800 UTC, 1900 UTC, and 2000 UTC RUC analysis soundings and the resulting CAPE when SB lifted parcels from corresponding KXVG observations are used. The SBCAPE increased between the warm front and dryline from 1800 UTC to 1900 UTC, and decreased by 2000 UTC after the dryline passage. Again, the vertical vorticity enhancement near the boundary intersection along with the increase in low- level buoyancy (enhanced stretching potential) around 1900 UTC (about $15 \mathrm{~min}$ before the tornado) at the apex of the well-defined clear slot resulted in a favorable setting for a tornado under the influence of a cold-core 500-mb low. Yet, it was unanticipated by NWS forecasters owing to lack of radar signatures and what appeared to be insufficient buoyancy.

\section{Discussion}

Along with the associated surface patterns, thermodynamic parameters (e.g., the presence of lowlevel CAPE and steep low-level lapse rates) were 


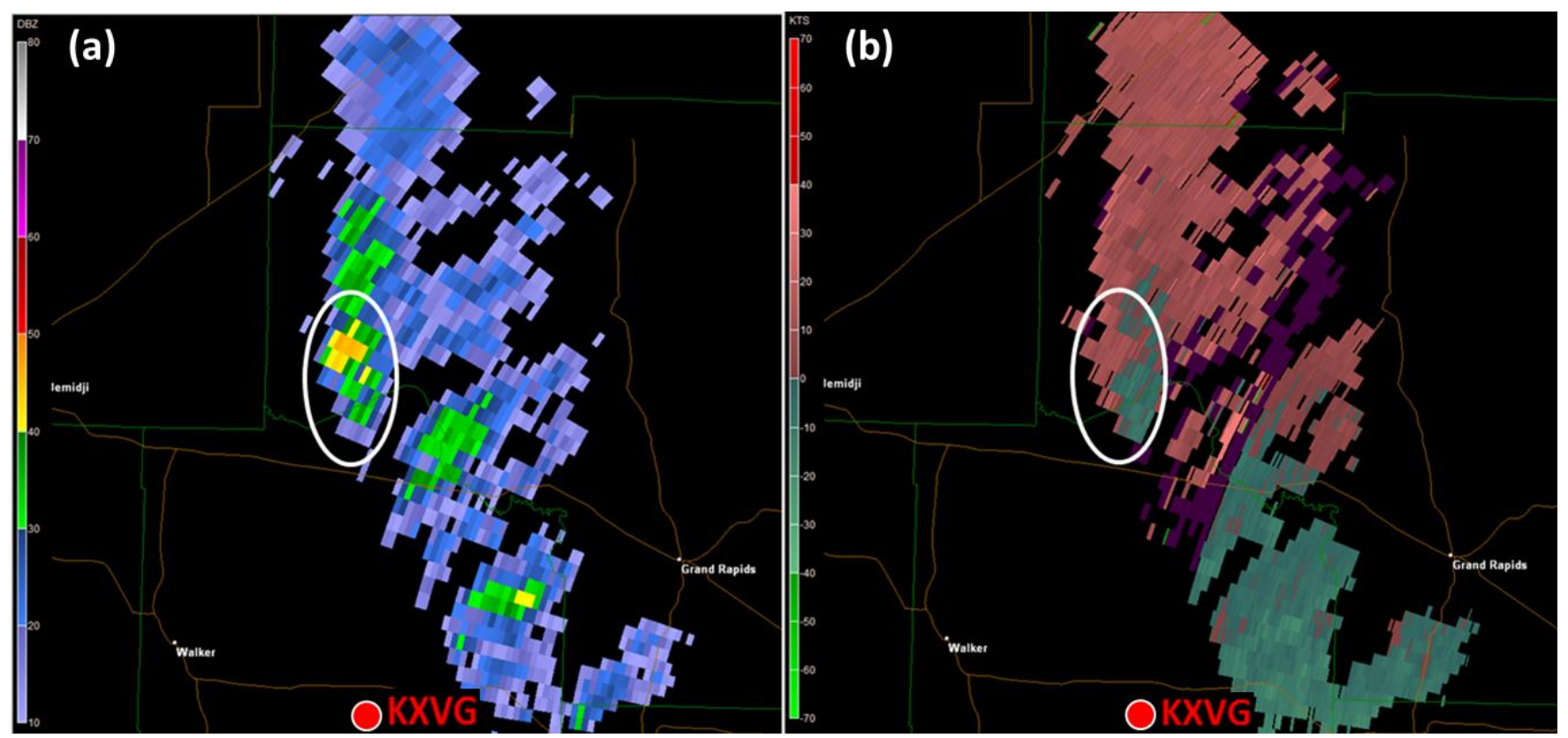

Figure 15. Same as Fig. 10 except for a closer view of the $0.5^{\circ}$ (a) base reflectivity and (b) storm-relative velocity radar images at 1914 UTC. The white oval encompasses the tornadic cell and the red dot denotes the location of the KXVG AWOS site.

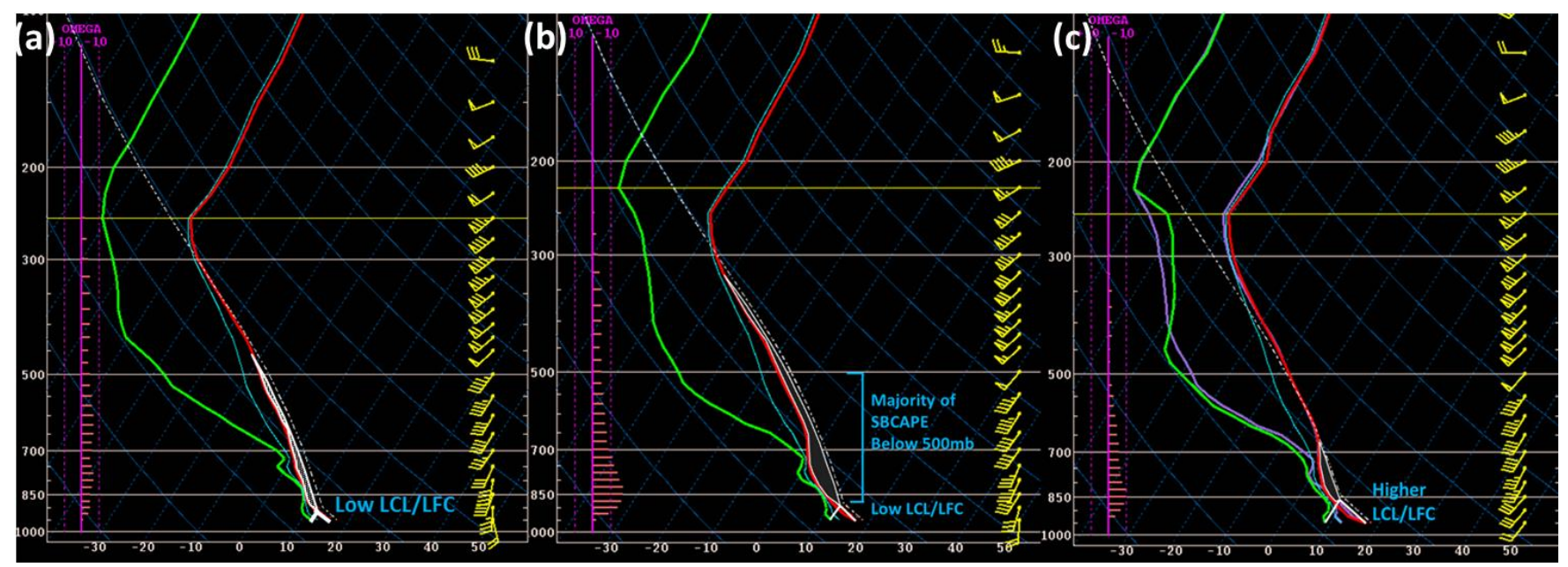

Figure 16. Skew/-log $p$ diagrams of RUC analysis profiles for Longville, MN, at (a) 1800 UTC, (b) 1900 UTC, and (c) 2000 UTC 26 May 2007. The red line is the temperature profile with the virtual temperature correction applied, the green line is the dewpoint profile $\left({ }^{\circ} \mathrm{C}\right)$, and the white outlined area with dotted fill is the SBCAPE after lifting a SB parcel using the associated KXVG AWOS observations.

emphasized in the cases presented in this paper. In contrast, vertical wind shear parameters such as $0-1-$ km BWD and 0-6-km BWD, while suggesting some support for tornadic supercells, showed little or no utility for discriminating between tornadic and nontornadic potential associated with cold-core 500$\mathrm{mb}$ lows in Guyer and Davies (2006). Also, similar to cases in Davies (2006a), composite parameters that combine thermodynamic ingredients and measures of low-level shear, such as the $0-1-\mathrm{km}$ energy-helicity index (EHI; Davies 1993), did not perform well in these cases (see Table 1), especially when compared to values associated with typical significant (F2/EF2 or greater) tornadic supercell environments (e.g., Rasmussen and Blanchard 1998; Brooks and Craven 2002; Thompson et al. 2003). Forecasters should understand that, apart from assessment of vertical CAPE distribution, composite thermodynamic/wind shear parameters (such as EHI and STP) usually do not perform well in highlighting tornado potential in coldcore cases because of the smaller total values of instability and low-level shear involved. This re- 
emphasizes the importance of pattern recognition in assessing cold-core settings with tornado potential (Davies 2006a).

One parameter that may warrant further investigation is the effective BWD (Thompson et al. 2007; also called effective bulk shear), which varies according to storm depth, unlike 0-6-km BWD (also commonly referred to as $0-6-\mathrm{km}$ shear or $0-6-\mathrm{km}$ bulk shear) that uses a fixed depth. The $0-6 \mathrm{~km}$ BWD was $\geq 18 \mathrm{~m} \mathrm{~s}^{-1}$ (35 kt) in these two cases, which suggests that the storms may have been supercellular (Rasmussen and Blanchard 1998). However, because the storms examined in this paper were relatively shallow in depth, effective BWD might be a more representative parameter than 0-6-km BWD for determining supercell potential in cold-core settings. Using the RUC analysis soundings to estimate effective BWD through the lower $50 \%$ of the storm depth (surface-to-equilibrium level in these cases), the 23 September 2004 and 26 May 2007 cases each had effective bulk wind difference values of $7.2 \mathrm{~m} \mathrm{~s}^{-1}$ and $12.9 \mathrm{~m} \mathrm{~s}^{-1}$ (14 kt and $25 \mathrm{kt}$, not shown), respectively. These values would place the storms in the "nonsupercell" or "marginal" categories using the 25th- to 75th-percentiles from Thompson et al. (2007). Determining whether or not effective BWD indicative of supercell or nonsupercell structure is a viable discriminating factor between tornadic and nontornadic events in cold-core cases warrants examination with a larger database of cases.

Cases that can be classified as "mini-supercells" (Grant and Prentice 1996) often present radar sampling problems. Grant and Prentice (1996) showed that a descending mesocyclone and maximum rotational velocity height falling to an average of $1800 \mathrm{~m}$ (5500 $\mathrm{ft}$ ) was a good indicator of the time of tornadogenesis in mini-supercells. In the two cases presented in this paper, the distance of the tornadic storm to the radar was about $160 \mathrm{~km}(100 \mathrm{mi})$ or greater, making the lowest beam height $>3300 \mathrm{~m}(10000 \mathrm{ft})$. Moreover, the echo tops of the tornadic storms were only 6000 $7700 \mathrm{~m}(20000-25000 \mathrm{ft})$ above radar level. Given these limitations, radar interrogation alone would be ineffective in anticipating tornadoes in these and similar cases.

There is no easy answer for how to handle these difficult tornadic events operationally. If limited tornadic radar signatures are present due to limitations in sampling, successful short-term warning operations are nearly impossible using radar data alone. However, increased awareness could be achieved by outlook products ahead of time when the pattern is recognized, and with vigilant mesoanalysis, successful warning operations are possible. Consider the following hypothetical example: the early-morning NWS forecaster determines that a cold-core low (as defined by DG04) will be moving over the area later that day and that there will be a warm front lifting north across the forecast area with dewpoints $>10^{\circ} \mathrm{C}\left(50^{\circ} \mathrm{F}\right)$ in the warm sector to the east of the low. While forecasted SBCAPE remains small for significant tornadoes with supercells ( $<1000 \mathrm{~J} \mathrm{~kg}^{-1}$ in this scenario), the NWS forecaster recognizes that this pattern is a potential setup for tornadoes in close proximity on the east side of the upper low. As in previous cases of tornadoes associated with cold-core lows, the SPC Day One Outlook also highlights the environment, stating that although buoyancy will be too small for widespread severe activity, surface heating and enhanced shear in the vicinity of the warm from may result in supercell/tornadoes if enough destabilization occurs. Exact threatened locations cannot be pinpointed in the early morning, but the forecaster can narrow the threat area to the intersection of the warm front and dryline to the east of the surface low during peak heating hours. The NWS forecaster then issues a Hazardous Weather Outlook (HWO) for the threat area, stating that conditions are favorable for tornadoes to develop rapidly during the afternoon with little warning. This outlook may raise the awareness of emergency officials, media, and the public, and serve to provide useful advanced notice. As the day progresses into the early afternoon, the NWS forecaster maintains close watch of the developing mesoscale conditions, looking for developing clear slots, monitoring trends of lowlevel lapse rates and low-level CAPE, and analyzing the surface data for a boundary intersection and enhanced vertical vorticity. It is also important that the forecaster take notice of actual observational data versus model analysis data to determine mesoscale trends in low-level instability that may not otherwise be accurately resolved.

Assuming mesoscale conditions appear favorable, the NWS forecaster monitors the radar closely for developing convection in the vicinity of the boundary intersection and issues a Special Weather Statement (SPS) for this more localized area mentioning possible rapid development of storms with the potential for tornadoes within the next few hours during peak heating. If convection develops and is approaching the boundary intersection, the threat for tornadoes increases significantly and the NWS forecaster must 
decide on a quick course of action. DG04 determined that when a boundary intersection with dewpoints $\geq 10^{\circ} \mathrm{C}\left(50^{\circ} \mathrm{F}\right)$ is present within $320 \mathrm{~km}$ (approximately $200 \mathrm{mi}$ ) of the upper cold-core low (as defined by DG04), the climatology study shows there is a $67 \%$ probability of at least one tornado occurring with the convection near said boundary intersection. That being stated, tornado warning operations often involve multiple warnings that would result in a higher falsealarm rate (FAR) than the climatology study suggests. Analyzing a subset of cold-core 500-mb low cases from the Guyer and Davies (2006) study (cases from 2005 , and one from 2014 that was not part of the Guyer and Davies 2006 study, Table 2), the author performed hypothetical tornado warning operations for eleven cases (seven tornadic, four null) based on the following criteria. Given the cold-core 500-mb definition (DG04) is satisfied, the following four criteria, based on the key ingredients found in DG04, Davies (2006a), and this paper, must be met before issuing a tornado warning:
1. a surface boundary intersection within roughly 320 $\mathrm{km}$ (approximately $200 \mathrm{mi}$ ) of the $500-\mathrm{mb}$ low center;

2. a sunshine axis adjacent to the boundary intersection;

3. convection (or developing convection) present immediately upstream of or on the boundary intersection; and

4. a vertical vorticity maximum that encompasses boundary intersection per SPC mesoanalysis graphics.

If all four of these key criteria were met, the author issued a tornado warning (regardless of radar signatures) using a polygon that encompassed the convection and its future track near the boundary intersection, including convection that extended northeastward or southeastward from the intersection up to $40-80 \mathrm{~km}(25-50 \mathrm{mi})$, depending on areal extent. The author continued issuing tornado warnings until these criteria ceased to be met or once the convection cleared the boundary intersection.

Table 2. Tabular list of cases used in warning experiment, and corresponding number of tornadoes and probability of detection/false-alarm rate statistics. The number of tornadoes was determined using SPC Storm Reports archive. If two tornado reports were within approximately $8 \mathrm{~km}(5 \mathrm{mi})$ and $<10 \mathrm{~min}$ apart, they were considered the same tornado, unless the comments in the SPC Storm Reports indicated otherwise. [* The exception is the 27 November 2005 case, when a full storm survey was completed and the conclusion was that 12 separate tornadoes occurred (www.crh.noaa.gov/news/display_cmsstory.php?wfo=top\&storyid=15794\&source=2).]

\begin{tabular}{|c|c|c|c|c|}
\hline Case Dates & Location of Interest & $\begin{array}{c}\text { Number of Tornadoes } \\
\text { Reported (Determined } \\
\text { from SPC Storm Reports) }\end{array}$ & $\begin{array}{c}\text { Probability of Detection } \\
\text { (POD) }\end{array}$ & False Alarm Rate (FAR) \\
\hline 01 April 2005 & Tyler, TX (KTYR) & 0 & N/A & 0.00 \\
\hline 10 April 2005 & Pratt, KS (KPTT) & 0 & N/A & 0.00 \\
\hline 22 April 2005 & Decatur, IL (KDEC) & 1 & 1.00 & 0.50 \\
\hline 08 May 2005 & Aberdeen, SD (KABR) & 1 & 1.00 & 0.75 \\
\hline 09 May 2005 & Faribault, MN (KFBL) & 0 & N/A & 0.00 \\
\hline 21 May 2005 & Crookston, MN (KCKN) & 1 & 1.00 & 0.50 \\
\hline 03 June 2005 & Liberal, KS (KLBL) & 2 & 1.00 & 0.50 \\
\hline 13 June 2005 & Alexandria, MN (KAXN) & 4 & 0.75 & 0.25 \\
\hline 30 September 2005 & Perryton, TX (KPYX) & 0 & N/A & 0.00 \\
\hline 27 November 2005 & Manhattan, KS (KMHK) & $12 *$ & 0.83 & 0.25 \\
\hline 31 March 2014 & Marshall, MN (KMML) & 2 & 0.50 & 0.50 \\
\hline
\end{tabular}

The results of this eleven case experiment were a probability of detection (POD) rate of $83 \%$, and a FAR of $45 \%$. A FAR of $45 \%$ is still well below the 2011 NWS tornado FAR of $74 \%$ per the 2012 State of the NWS (www.ametsoc.org/boardpges/cwce/docs/Stateof-Enterprise/State-of-the-National-Weather-Servicein-2012.pdf) and suggests that there is utility in this warning method. The decision to issue tornado warning(s) on these cells despite lack of tornadic signatures on radar is unarguably very difficult, but potentially justifiable given the high probability of a tornado occurrence, per DG04, and the results of the eleven case experiment performed by the author. In addition, aggressive interrogation of storm spotters and emergency managers in the area in order to receive confirmation is suggested, as these tornadoes tend to be short-lived. These storm reports could also improve POD and FAR by helping decide whether or not to continue issuing warnings. Tornado warnings are not suggested when these fairly objective key criteria are 
not in place, but these criteria should also be used only as guidelines and not hard requirements, depending on a forecaster's experience. The fundamental points are 1) to recognize the pattern and important mesoscale features and 2) to communicate that threat effectively without grossly over-warning for these cold-core low tornadic setups.

Using the 23 September 2004 case as an example (Fig. 17), issuing a 45-min tornado warning for the line of convection approaching the boundary intersection based on the radar image at 1924 UTC (the time when the clear slot had developed) would have given a lead time of approximately $35 \mathrm{~min}$. The convection had passed the boundary intersection at the end of the 45-min warning, so no additional tornado warnings would have been issued. Of course, hindsight is perfect and no case is or will be exactly like the ones in this paper, but documenting and reviewing cases like these should help increase awareness and warning skills in the future.

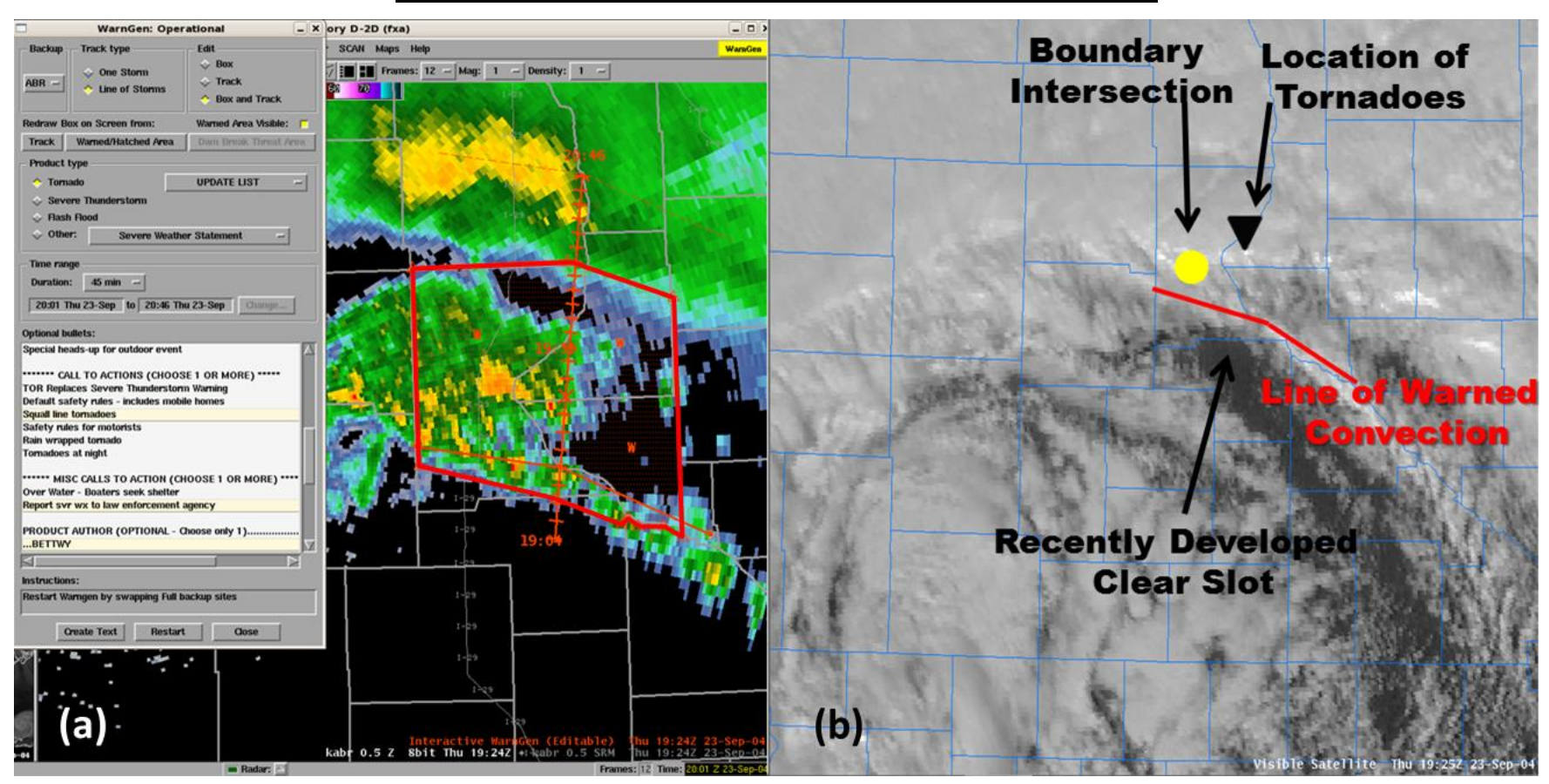

Figure 17. (a) $0.5^{\circ}$ base reflectivity from the KABR WSR-88D at 1924 UTC 23 September 2004-the time of the recommended tornado warning issuance. The NWS warning generation software (WarnGen) interface is displayed on the left, and the red polygon is the area of the recommended 45-min tornado warning. The red line with dash marks is the distance/speed tool used by WarnGen. (b) Visible satellite image at 1925 UTC 23 September 2004 with the locations of the boundary intersection, impending tornadoes, recently developed clear slot, and line of the recommended tornado-warned convection annotated.

\section{Conclusions}

Several factors must come together in order for tornadoes associated with cold-core 500-mb lows to occur. Assuming a 500-mb cold core low (as defined by DG04) is or will be present, forecasters should increase vigilance regarding favorable factors for tornadogenesis. In the cases presented in this paper, the favorable factors included the intersection of surface boundaries near the tip of heating axes to the east and within $320 \mathrm{~km}$ (approximately $200 \mathrm{mi}$ ) of the $500-\mathrm{mb}$ low, resulting in an increase in low-level instability while maintaining low LCLs. Additionally, Guyer and Davies (2006) showed that the 0-3-km CAPE was considerably higher in tornadic cases than in null events, which also proved true for the cases in this paper as the bulk of the CAPE resided below 500 mb. Besides the location of the convection, radar interrogation may be of little help when searching for tornadic signatures if the storms are far from the radar. This hindrance is mainly due to the low tops of these tornadic storms, resulting in poor radar sampling, especially at a distance approximately $>97 \mathrm{~km}(60 \mathrm{mi})$ with a $0.5^{\circ}$-beam height of more than approximately $1800 \mathrm{~m}(5500 \mathrm{ft})$ based on the findings in Grant and Prentice (1996). Both cases exhibited in this paper fit well into the conceptual schematic of tornadoes associated with $500-\mathrm{mb}$ cold-core lows that was presented in Davies (2006a). It is recommended that 
when these key conditions exist and convection develops near the boundary intersection, tornado warnings be considered as outlined in section 3 of this paper, even if tornadic signatures are not evident on the radar.

Acknowledgments. The author thanks Phil Schumacher (NWS, Sioux Falls, SD) for his insightful and thorough reviews of this paper, along with his helpful guidance. The author is also very grateful to Jared Guyer (SPC, Norman, $\mathrm{OK}$ ) for his great help in providing data and guidance. Thank you also goes to Josh Boustead (NWS, Omaha, NE) and Mike Bettwy (NWS Aviation Weather Center, Kansas City, MO) for their helpful, detailed, and constructive feedback for this paper. Finally, thank you to formal reviewers Jon Davies (private meteorologist) and Rich Thompson (SPC, Norman, OK) for providing thoughtful suggestions and edits for improving this paper. The views expressed are those of the author and do not necessarily represent those of the National Weather Service.

\section{REFERENCES}

Bothwell, P. D., J. A. Hart, and R. L. Thompson, 2002: An integrated three-dimensional objective analysis scheme in use at the Storm Prediction Center. Preprints, 21st Conf. on Severe Local Storms, San Antonio, TX, Amer. Meteor. Soc., JP3.1. [Available online at ams.confex.com/ams/pdfpapers/47482.pdf.]

Brooks, H. E., and J. P. Craven, 2002: A database of proximity soundings for significant severe thunderstorms, 1957-1993. Preprints, 21st Conf. on Severe Local Storms, San Antonio, TX, Amer. Meteor. Soc., 16.2A. [Available online at ams.confex.com/ams/pdfpapers/46680.pdf.]

Cooley, J. R., 1978: Cold air funnel clouds. Mon. Wea. Rev., 106, 1368-1372, CrossRef.

Davies, J., 1993: Hourly helicity, instability, and EHI in forecasting supercell tornadoes. Preprints, 17th Conf. on Severe Local Storms, St. Louis, MO, Amer. Meteor. Soc., 107-111. , 2006a: Tornadoes with cold core 500-mb lows. Wea. Forecasting, 21, 1051-1062, CrossRef. , 2006b: Tornadoes in environments with small helicity and/or high LCL heights. Wea. Forecasting, 21, 579594, CrossRef.

, and J. L. Guyer, 2004: A preliminary climatology of tornado events with closed cold core 500-mb lows in the central and eastern United States. Preprints, 22nd Conf. on Severe Local Storms, Hyannis, MA, Amer. Meteor. Soc., 7B.4. [Available online at ams.confex.com/ams/pdfpapers/81563.pdf.]

Davies-Jones, R. P., D. Burgess, and M. Foster, 1990: Test of helicity as a tornado forecast parameter. Preprints, 16th Conf. on Severe Local Storms, Kananaskis Park, AB, Canada, Amer. Meteor. Soc., 588-592.

Doswell, C. A., III, and E. N. Rasmussen, 1994: The effect of neglecting the virtual temperature correction on CAPE calculations. Wea. Forecasting, 9, 625-629, CrossRef.

Grant, B. N., and R. Prentice, 1996: Mesocyclone characteristics of mini supercell thunderstorms. Preprints, 15th Conf. on Weather Analysis and Forecasting, Norfolk, VA, Amer. Meteor. Soc., 362-365. [Available online at www.wdtb.noaa.gov/modules/minimeso/minimeso.htm.]

Guyer, J. L., and J. M. Davies, 2006: Environment characteristics associated with tornado events near closed cold core $500 \mathrm{mb}$ lows. Preprints, 23nd Conf. on Severe Local Storms, St. Louis MO, P1.1. [Available online at ams.confex.com/ams/23SLS/techprogram/paper_11533 5.htm.]

Rasmussen, E. N., 2003: Refined supercell and tornado forecast parameters. Wea. Forecasting, 18, 530-535, CrossRef. , and D. O. Blanchard, 1998: A baseline climatology of sounding-derived supercell and tornado forecast parameters. Wea. Forecasting, 13, 1148-1164, CrossRef.

Thompson, R. L., R. Edwards, J. A. Hart, K. L. Elmore, and P. Markowski, 2003: Close proximity soundings within supercell environments obtained from the Rapid Update Cycle. Wea. Forecasting, 18, 1243-1261, CrossRef. , C. M. Mead, and R. Edwards, 2007: Effective stormrelative helicity and bulk shear in supercell thunderstorm environments. Wea. Forecasting, 22, 102-115, CrossRef.

Togstad, W. E., J. M. Davies, S. J. Corfidi, D. R. Bright, and A. R. Dean, 2011: Conditional probability estimation for significant tornadoes based on Rapid Update Cycle (RUC) profiles. Wea. Forecasting, 26, 729-743, CrossRef. 